\title{
Association between Cullin-3 Single-Nucleotide Polymorphism rs17479770 and Essential Hypertension in the Male Chinese Han Population
}

\author{
Jin Li, ${ }^{1,2}$ Jing Hu, ${ }^{3}$ Rong Sun, ${ }^{4}$ Yongpan Zhao, ${ }^{1}$ Heping Liu, ${ }^{2}$ Jian $\mathrm{Li}^{2}{ }^{2}$ Lei Shi, ${ }^{2}$ and \\ Shujin Zhao ${ }^{1,2}$ \\ ${ }^{1}$ School of Bioscience and Bioengineering, South China University of Technology, Guangzhou, China \\ ${ }^{2}$ Department of Pharmacy, Guangzhou General Hospital of Guangzhou Military Command, Guangzhou, China \\ ${ }^{3}$ Department of Nephrology, Guangzhou General Hospital of Guangzhou Military Command, Guangzhou, China \\ ${ }^{4}$ Futian District Chronic Disease Prevention and Cure Center, Shenzhen, China
}

Correspondence should be addressed to Lei Shi; lucyshi622921@163.com and Shujin Zhao; gzzsjzhs@163.com

Received 25 March 2017; Revised 23 May 2017; Accepted 25 May 2017; Published 18 July 2017

Academic Editor: Zhongjie Shi Copyright ( $) 2017 \mathrm{Jin} \mathrm{Li}$ et al. This is an open access article distributed under the Creative Commons Attribution License, which
permits unrestricted use, distribution, and reproduction in any medium, provided the original work is properly cited.

\begin{abstract}
Background. Hypertension, including essential and secondary hypertension, is a multifactorial disease, affecting more than one billion people worldwide. Secondary hypertension can result from mutations of cullin-3 (CUL3); however, whether polymorphisms of CUL3 are associated with essential hypertension (EH) has not been reported. Here, we investigated the association between CUL3 SNPs rs17479770 and rs3738952 and EH in the Chinese Han population. Methods. This casecontrol study investigated 520 representatives, including 259 patients with $\mathrm{EH}$ and 261 normotensive controls matched for age, gender, BMI, TG, TC, and HbAlc for the distribution of functional rs17479770 and rs3738952 within the CUL3 gene by using PCR and RFLP. Results. Our results showed that there was no significant difference in allele and genotype distribution of rs3738952 and haplotype distribution of rs17479770 and rs3738952 between the EH group and normotensive group, whereas the rs17479770 TT genotype in male and the full data set were significantly associated with the decreased risk of $\mathrm{EH}(P=0.050, P=0.042)$, and rs17479770 allele $\mathrm{T}$ in male was shown to have the correlation tendency of the decreased risk of $\mathrm{EH}(P=0.064)$. Conclusion. Our data suggest that the CUL3 rs 17479770 variant could be a protective factor in the pathogenesis of $\mathrm{EH}$.
\end{abstract}

\section{Introduction}

Cullin-3 (CUL3) is the core component of multiple cullinRING-based BCR (BTB-CUL3-RBX1) E3 ubiquitin-protein ligase complexes which mediate the ubiquitination and subsequent proteasomal degradation of target proteins [1]. The CUL3-RING E3 ubiquitin ligase (CRL) complex controls the ubiquitination of with-no-lysine kinase (WNK) and enhances the levels of WNK isoforms, whose function is similar to that of a serine-threonine protein kinase critical in controlling potassium, sodium, and $\mathrm{pH}$ homeostasis. The CRL complex also plays a major role in regulating blood pressure by increased activity of ion cotransporters in the kidney $[2,3]$. Through stabilizing WNK isoforms, the mutation of CUL3 has been linked to Pseudohypoaldosteronism type II (PHAII), a rare Mendelian syndrome featuring hypertension [4]. Vascular actions of CUL3 may contribute to hypertension, because McCormick and colleagues proposed that CUL3 regulates vascular tone via RhoA/Rho kinase signaling [5].

Hypertension is considered one of the most important diseases with a great burden on health care systems around the world. Hypertension is highly prevalent in the AsiaPacific [6]. About 2 million 430 thousand people died of hypertension, accounting for about $24.6 \%$ of all deaths in China in 2010. In 2013, China's total health expenditure is 
31869 billion yuan, of which the direct economic burden of hypertension accounted for $6.61 \%$ [7]. Essential hypertension $(\mathrm{EH})$, which accounts for $90 \%$ of hypertensive cases, is a polygenic and multifactorial disease caused by the interaction of genetic determinants and environmental factors $[8,9]$. The pathogenesis and etiology of $\mathrm{EH}$ include a multifactorial imbalance which results from complicated gene-gene and gene-environment interaction [10].

Single-nucleotide polymorphisms (SNPs) are the variation in the genomes which can be used to associate genotypic variation with the phenotype [11]. SNPs underlie differences in our susceptibility to disease. Associations of some SNPs in WNK1 and WNK4 with EH have been observed in the general population [12-14], and one study had identified that rs3738952 of CUL3 was significantly associated with head and neck squamous cell carcinoma (HNSCC) risk [15], but very few reports investigated the relationship between SNPs of CUL3 and EH [16]. Genome linkage studies have identified numerous gene variants that associated with $\mathrm{EH}$, and a few genetic loci and candidate genes (variants) have been identified by genome-wide association studies (GWAS) [17]. Through GWAS, a variety of common genetic variants are analyzed and identified for disease association, which have potential association with blood pressure and the development of $\mathrm{EH}[18,19]$, whereas some gene variants have been shown to have contribution to $\mathrm{EH}$ according to ethnicity or gender [20]. The development of genetic studies has revealed that some SNPs within genes, such as $A T P 1 B 1$ [21], CD36 [22], CYP2J2 [23], CYP4A11 [24, 25], CYP4F2 [26], CYP17A1 [27], and TPRC6 [28], are closely related to the progression of $\mathrm{EH}$.

However, it remains unknown whether there are other new gene variants which can influence the progression of EH. Therefore, we selected rs17479770 and rs3738952 SNPs in the CUL3 gene after the haploview analysis in the Han population of China and examined the possible relationship between the SNPs and EH in this study. Haploview software was used to conduct linkage disequilibrium and haplotype block analyses, using the Hapmap phase IV genotype data for chromosomal region 2: 225043534-225157486 (CHB database, Hapmap release 24 (2008, November)). The criterion for $r^{2}$ was set at 0.8 . The Han population is the largest ethnic group in China, and the association of CUL3 with $\mathrm{EH}$ in the Chinese Han population has not yet been reported. Therefore, our results could provide new insights into the pathogenesis of EH by studying CUL3 SNPs.

\section{Patients and Methods}

2.1. Ethics. The present study was performed with the approval of the ethics committee of Guangzhou General Hospital of Guangzhou Military Command and is in compliance with the Helsinki Declaration. Informed consents were collected from all the candidate subjects.

2.2. Subjects. Patients diagnosed with EH were recruited from Guangzhou General Hospital of Guangzhou Military Command from 2012 to 2015. In total, 259 patients in the $\mathrm{EH}$ patient group and 261 control subjects in the
TABLE 1: Baseline of the study population.

\begin{tabular}{lccc}
\hline Parameters & $\begin{array}{c}\text { EH group } \\
(n=259)\end{array}$ & $\begin{array}{c}\text { Normotensive group } \\
(n=261)\end{array}$ & $P$ \\
\hline Age, y & $77.81 \pm 7.640$ & $76.78 \pm 9.095$ & $0.163^{*}$ \\
Gender, male, \% & $50.2 \%$ & $50.9 \%$ & 0.930 \\
BMI & $23.654 \pm 3.871$ & $23.305 \pm 3.754$ & $0.297^{*}$ \\
HbAlc, \% & $5.3286 \pm 0.901$ & $5.258 \pm 0.871$ & $0.364^{*}$ \\
TC, mmol/L & $4.448 \pm 0.893$ & $4.327 \pm 0.836$ & $0.111^{*}$ \\
TG, $\mathrm{mmol} / \mathrm{L}$ & $1.436 \pm 0.926$ & $1.346 \pm 1.141$ & $0.324^{*}$ \\
\hline
\end{tabular}

${ }^{*}$ Analyzed by one-way ANOVA.

normotensive group, matched for age, sex, BMI, TG, TC, and $\mathrm{HbAlc}$, were enrolled in this study (Table 1). All of the $\mathrm{EH}$ patients received antihypertensive drug treatment, so it does not need to match the blood pressure between the two groups. All participants were unrelated and belonged to the Chinese Han population. $\mathrm{EH}$ patients were diagnosed according to JNC 7 [29] and JNC 8 [30]: systolic blood pressure (SBP) $>140 \mathrm{mmHg}$ and diastolic blood pressure $(\mathrm{DBP})>90 \mathrm{mmHg}$, without any antihypertensive medication or confirmed diagnosis of $\mathrm{EH}$ by a cardiovascular specialist. The subjects who had secondary hypertension caused by another disease or are in the acute phase with cardiovascular, lung, liver, kidney, and other somatic diseases or with malignant tumor were excluded from the $\mathrm{EH}$ patient group. The normotensive group was selected based on the following criteria: SBP $<129 \mathrm{mmHg}$ and $\mathrm{DBP}<85 \mathrm{mmHg}$ and without any antihypertensive medication. Subjects who had been currently diagnosed with malignant tumor and diabetes or in the acute phase with cardiovascular, lung, liver, kidney, and other somatic diseases were excluded from the normotensive group. One subject with diabetes in the $\mathrm{EH}$ patient group was excluded, and one subject with impaired glucose tolerance in the normotensive group was also excluded from analysis.

2.3. DNA Extraction. Genomic DNA was extracted from circulating leukocytes using commercial DNA isolation kits (Tiangen Biotech, Beijing, China). Briefly, the red blood cells, as well as the nuclei of leukocytes, were lysed. Subsequently, proteins were precipitated, followed by the precipitation of DNA using isopropanol. The DNA pellet was washed with ethanol. Finally, DNA was rehydrated with the DNA Rehydration Solution and preserved in liquid nitrogen.

2.4. Genotyping. Genomic DNA was isolated from peripheral blood leukocytes, according to the standard procedures by using commercial DNA isolation kits (Tiangen Biotech, Beijing, China). We performed genotyping for CUL3 rs17479770 and rs3738952 polymorphisms by matrixassisted laser desorption/ionization time-of-flight mass spectrometry (MALDI-TOF MS) by using the Sequenom Mass ARRAY system (Sequenom Inc., CA, USA). Primers used for genotyping were designed manually: rs17479770 forward 5'-TGCCA TTTCCTGCTAGCAACCT-3' and reverse 5'- 
TCTTGGAAGGAAAGCTGTTGCATA-3' ${ }^{\prime}$ and rs3738952 forward $5^{\prime}$-CCCAGGTCAACATAAATCACACATCA- $3^{\prime}$ and reverse $5^{\prime}$-TTCTGCAGATCTCAATG CCACAT- 3 '. The concentration of rs 17479770 primers was $1 \mu \mathrm{M}$, and that of rs3738952 primers was $2 \mu \mathrm{M}$ in the PCR reaction system. PCR was performed in a reaction mixture volume of $20 \mu \mathrm{L}$, which included $1 \times$ HotStarTaq buffer, $3.0 \mathrm{mM} \mathrm{Mg}^{2+}$, $0.3 \mathrm{mM}$ dNTP, $1 \mathrm{U}$ HotStarTaq polymerase (Qiagen Inc., $\mathrm{MD}, \mathrm{USA}$ ), and $1 \mu \mathrm{L}$ DNA template. Amplification was performed under the following conditions: initial denaturation of 2 min at $95^{\circ} \mathrm{C}$ followed by 11 cycles of denaturation at $94^{\circ}$ $\mathrm{C}$ for $20 \mathrm{~s}$, annealing at $59.5^{\circ} \mathrm{C}$ for $40 \mathrm{~s}$, and extension at $72^{\circ}$ $\mathrm{C}$ for $1 \mathrm{~min}$ and $30 \mathrm{~s}$ and 24 cycles of denaturation at $94^{\circ} \mathrm{C}$ for $20 \mathrm{~s}$, annealing at $59^{\circ} \mathrm{C}$ for $30 \mathrm{~s}$, and extension at $72^{\circ} \mathrm{C}$ for $1 \mathrm{~min}$ and $30 \mathrm{~s}$ followed by a final extension at $72^{\circ} \mathrm{C}$ for $2 \mathrm{~min}$. PCR products were stored at $4^{\circ} \mathrm{C}$. Restriction DNA fragments were separated by electrophoresis on $1 \%$ agarose gel and stained with ethidium bromide.

Linking primers used for coupled reaction for genotyping were designed manually: rs17479770RC, TTCCGCGTTCG GACTGATATTCAGCAAAATTAGAAGTCATTTCTAGT CCTGAG; rs17479770RP2, AGCAGAARTAATTAGAAA TGTTAACATTTAAGTGCTTTTTTTTTTT; rs17479770 RT, TACGGTTATTCGGGCTCCTGTTCAGCAAAATT AGAAGTCATTTCTAGTCCTGAA; rs3738952RC, TCT CTCGGGTCAATTCGTCCTTTCTCAATGCCACATTTT ATGGACAAG; rs3738952RP, TTAAAAAGGTAAATAT TGATAGTTTGAACGTATTAAGTAATTTTT; and rs373 8952RT, TGTTCGTGGGCCGGATTAGTTCTCAATGC CACATTTTATGGACGAA. The reaction system of coupled reaction was performed in a reaction mixture system including $1 \mu \mathrm{L} 10 \times$ connection buffer, $0.25 \mu \mathrm{L}$ ligase, and $0.4 \mu \mathrm{L} 5^{\prime}$ primer mixture (1 connection $\mathrm{M}$ ) and $0.4 \mu \mathrm{L} 3^{\prime}$ primer mixture ( 2 connection $\mathrm{M}$ ), after purification of $2 \mu \mathrm{L}$ multiple PCR products and $6 \mu \mathrm{L} \mathrm{ddH}_{2} \mathrm{O}$ mixture. Coupled reaction was performed under the following conditions: 38 cycles of denaturation at $94^{\circ} \mathrm{C}$ for $1 \mathrm{~min}$ and annealing at $56^{\circ} \mathrm{C}$ for $4 \mathrm{~min}$. Reaction products were stored at $4^{\circ} \mathrm{C}$. Allelic discrimination was measured automatically on the ABI3730XL (Applied Biosystems) using the GeneMapper 4.1 software ( $95 \%$ confidence intervals).

2.5. Statistical Analysis. Statistical analysis was performed using the SPSS 20.0 software (SPSS Inc., Chicago, IL, USA).

The haplotype of rs17479770 and rs3738952 was analyzed by PHASE 2.0 (University of Manchester, Manchester, UK). One-way ANOVA was used to match the values of BMI, HbAlc, TC, and TG between the EH patient group and normotensive group. The chi-squared test was used to examine whether the genotype distributions differed from the expected Hardy-Weinberg equilibrium (HWE) and the distribution of rs17479770 and rs3738952 genotypes and alleles between the EH patient group and normotensive group. Odds ratios (OR) and its corresponding 95\% confidence intervals (CI) were estimated to compare the distribution of genotypes and alleles between the patients and control subjects. Analyses used two-tailed estimation of significance. $P<0.05$ was considered to be statistically significant.

\section{Results}

3.1. Baseline Characteristics of the Study Population. The Han population consisted of 259 patients in the $\mathrm{EH}$ patient group (130 males and 129 females with an average age of 77.81 \pm 7.640 years old) and 261 control subjects in the normotensive group (133 males and 128 females with an average age of $76.78 \pm 9.095$ years old), and there was no significant difference in age between the two groups $(P=0.163)$. The gender ratio of the two groups was insignificant $(P=0.930)$. The clinical representative characteristics including ID, age, gender, height, weight, TG, TC, and HbAlc were collected. There were no significant differences between the two groups including BMI, HbAlc, TC, and TG ( $P$ values were 0.297, $0.364,0.111$, and 0.324 , resp.) (Table 1 ). The systolic blood pressure (SBP) and diastolic blood pressure (DBP) values were not included because all $\mathrm{EH}$ patients received antihypertensive medication.

3.2. Allele and Genotype Frequencies of CUL3 rs 17479770 and rs3738952 in the EH Patient Group and Normotensive Group. The allele and genotype frequencies of rs17479770 and rs3738952 SNPs are shown in Tables 2 and 3. Genotype distribution in the $\mathrm{EH}$ patient group and normotensive group did not deviate from HWE $(P>0.05)$. Comparison of allele frequencies between the patient group and normotensive group by the chi-squared test revealed that the allele and genotype frequencies of rs3738952 had no statistically significant difference between the $\mathrm{EH}$ patient group and the normotensive group (Table 3), whereas the rs17479770 TT genotype in males and the full data set had a significantly protective effects on EH $(P=0.050 ; \quad \mathrm{OR}=0.578,95 \%$ $\mathrm{CI}=0.344-0.970 ; \quad P=0.042 ; \quad \mathrm{OR}=0.674,95 \% \quad \mathrm{CI}=0.468-$ 0.971 ) (Table 2) and the T allele in males and the CT genotype in the full data set show some protective trend of $\mathrm{EH}$ $(P=0.064 ; P=0.066)$. When the data further stratified the haplotype frequency distributions of CUL3 rs17479770 and rs3738952 SNPs, there is no statistically significant difference between the $\mathrm{EH}$ patient group and normotensive group (Table 4).

Overall, these results suggest that the TT genotype of rs17479770 in males and all representatives indicate a significantly protective effect on $\mathrm{EH}$ and the $\mathrm{T}$ allele shows some protective trend to the male representatives and the same as the CT genotype to all representatives.

\section{Discussion}

We investigated rs17479770 and rs3738952 SNPs in the CUL3 gene as genetic risk factors for $\mathrm{EH}$ in a case-control study of a well-characterized Southern Chinese Han population. Our results demonstrate that the frequencies of the rs17479770 TT genotype in male EH patients and in all representatives were significantly decreased compared to those in the normotensive group, whereas there was no statistically significant difference in allele and genotype frequencies of CUL3 in males between the EH patient group and the normotensive group. Moreover, there was no significant difference of haplotype frequency distributions of the two SNPs 
TABLE 2: Distribution frequency of CUL3 rs17479770 polymorphism in the EH and control groups.

\begin{tabular}{|c|c|c|c|c|c|c|}
\hline & CUL3 & $\begin{array}{l}\mathrm{rs} 17479770 \\
(\mathrm{C} / \mathrm{T})\end{array}$ & $\begin{array}{l}\text { EH group } \\
n\end{array}$ & $\begin{array}{l}\text { Normotensive group } \\
n\end{array}$ & $P$ & OR (95\% CI) \\
\hline \multirow{5}{*}{ Full data set } & \multirow{2}{*}{ Allele } & $\mathrm{C}$ & 229 & 207 & & \\
\hline & & $\mathrm{T}$ & 289 & 317 & 0.132 & $1.213(0.948-1.553)$ \\
\hline & \multirow{3}{*}{ Genotype } & $\mathrm{CC}$ & 47 & 46 & 0.909 & $1.041(0.665-1.630)$ \\
\hline & & $\mathrm{CT}$ & 135 & 115 & 0.066 & $1.392(0.986-1.965)$ \\
\hline & & TT & 77 & 101 & 0.042 & $0.674(0.468-0.971)$ \\
\hline \multirow{5}{*}{ M } & \multirow{2}{*}{ Allele } & $\mathrm{C}$ & 121 & 102 & & \\
\hline & & $\mathrm{T}$ & 139 & 164 & 0.064 & $1.400(0.989-1.980)$ \\
\hline & \multirow{3}{*}{ Genotype } & $\mathrm{CC}$ & 27 & 22 & 0.430 & $1.323(0.709-2.467)$ \\
\hline & & $\mathrm{CT}$ & 67 & 58 & 0.218 & $1.375(0.846-2.235)$ \\
\hline & & TT & 36 & 53 & 0.050 & $0.578(0.344-0.970)$ \\
\hline \multirow{5}{*}{$\mathrm{F}$} & \multirow{2}{*}{ Allele } & $\mathrm{C}$ & 108 & 107 & & \\
\hline & & $\mathrm{T}$ & 150 & 151 & 1.000 & $1.016(0.716-1.442)$ \\
\hline & \multirow{3}{*}{ Genotype } & $\mathrm{CC}$ & 20 & 25 & 0.512 & $0.763(0.400-1.457)$ \\
\hline & & $\mathrm{CT}$ & 68 & 57 & 0.213 & $1.408(0.863-2.299)$ \\
\hline & & $\mathrm{TT}$ & 41 & 47 & 0.512 & $0.813(0.485-1.361)$ \\
\hline
\end{tabular}

TABLE 3: Distribution frequency of CUL3 rs3738952 polymorphism in the EH and control groups.

\begin{tabular}{|c|c|c|c|c|c|c|}
\hline & CUL3 & $\begin{array}{l}\text { rs3738952 } \\
\quad(\mathrm{C} / \mathrm{T})\end{array}$ & $\begin{array}{c}\text { EH group } \\
n\end{array}$ & $\begin{array}{c}\text { Normotensive group } \\
n\end{array}$ & $P$ & OR $(95 \% \mathrm{CI})$ \\
\hline \multirow{5}{*}{ Full data set } & \multirow{2}{*}{ Allele } & $\mathrm{C}$ & 387 & 399 & & \\
\hline & & $\mathrm{T}$ & 131 & 123 & 0.564 & $0.911(0.686-1.209)$ \\
\hline & \multirow{3}{*}{ Genotype } & $\mathrm{CC}$ & 145 & 151 & 0.723 & $0.927(0.655-1.311)$ \\
\hline & & $\mathrm{CT}$ & 97 & 97 & 1.000 & $1.012(0.710-1.444)$ \\
\hline & & TT & 17 & 13 & 0.459 & $1.340(0.637-2.819)$ \\
\hline \multirow{5}{*}{ M } & \multirow{2}{*}{ Allele } & $\mathrm{C}$ & 201 & 204 & 0.368 & $1.202(0.810-1.786)$ \\
\hline & & $\mathrm{T}$ & 59 & 72 & & \\
\hline & \multirow{3}{*}{ Genotype } & $\mathrm{CC}$ & 76 & 79 & 0.901 & $0.962(0.589-1.572)$ \\
\hline & & CT & 49 & 46 & 0.610 & $1.144(0.692-1.893)$ \\
\hline & & $\mathrm{TT}$ & 5 & 8 & 0.572 & $0.625(0.199-1.963)$ \\
\hline \multirow{5}{*}{$\mathrm{F}$} & \multirow{2}{*}{ Allele } & $\mathrm{C}$ & 186 & 195 & 0.315 & $0.808(0.544-1.201)$ \\
\hline & & $\mathrm{T}$ & 72 & 61 & & \\
\hline & \multirow{3}{*}{ Genotype } & $\mathrm{CC}$ & 69 & 72 & 0.707 & $0.894(0.547-1.462)$ \\
\hline & & $\mathrm{CT}$ & 48 & 51 & 0.702 & $0.895(0.541-1.479)$ \\
\hline & & $\mathrm{TT}$ & 12 & 5 & 0.130 & $2.523(0.862-7.382)$ \\
\hline
\end{tabular}

of CUL3 in the EH patient group and normotensive group. The results of statistical analysis suggest that all CUL3 rs17479770 TT genotypes were associated with the protection of the Chinese Han population especially male subjects from $\mathrm{EH}$

RhoA activation contributes to vascular constriction and hypertension, and CUL $3 \Delta 9$-associated ubiquitin ligase activity toward RhoA is impaired, suggesting that CUL3 $\Delta 9$ mutations may act dominantly by sequestering substrate adaptors and disrupting CUL3WT complexes [16]. CUL3 and KLHL3 are expressed in the distal nephron of the kidney, suggesting a mechanistic link between KLHL3 and CUL3 mutations, increased $\mathrm{Na}^{+}-\mathrm{Cl}^{-}$reabsorption, and disease pathogenesis [31]. CUL3 provides a scaffold that binds to the BTB domain of KLHL3 through its N-terminus region [32]. WNK1 and WKN4 regulate sodium and potassium flux through regulation of the thiazide-sensitive $\mathrm{Na}^{+} / \mathrm{Cl}^{-}$cotransporter (NCC) and the renal outer medullary potassium channel (ROMK) in the distal nephron $[33,34]$. The WNK1 and WNK4 isoforms, through directing two homologous kinases, SPS1related proline/alanine-rich kinase (SPAK, also known as serine threonine kinase 39, STK39) and oxidative stressresponsive kinase1 (OSR1) which phosphorylates and activates $\mathrm{NCC}$ and $\mathrm{Na}^{+} / \mathrm{K}^{+} / 2 \mathrm{Cl}^{-}$cotransporters (NKCC) 1 and 
TABLE 4: Haplotype frequency distributions of the 2 SNPs of CUL3 in the EH and normotensive groups.

\begin{tabular}{lcccccc}
\hline CUL3 & Haplotype & EH group ratios & Normotensive group ratios & $\chi^{2}$ & $P$ value & OR (95\% CI) \\
\hline \multirow{3}{*}{ Full data set } & CC & $229: 259$ & $207: 261$ & 0.700 & 0.436 & $1.115(0.864-1.438)$ \\
& TC & $158: 259$ & $192: 261$ & 1.824 & 0.189 & $0.829(0.632-1.088)$ \\
& TT & $131: 259$ & $123: 261$ & 0.213 & 0.647 & $1.073(0.795-1.449)$ \\
Male & CC & $121: 130$ & $102: 133$ & 1.128 & 0.317 & $1.214(0.849-1.735)$ \\
& TC & $80: 130$ & $102: 133$ & 1.293 & 0.288 & $0.802(0.549-1.173)$ \\
& TT & $59: 130$ & $62: 133$ & 0.015 & 0.913 & $0.974(0.633-1.498)$ \\
\multirow{3}{*}{ Female } & CC & $108: 129$ & $105: 128$ & 0.012 & 0.926 & $1.021(0.710-1.468)$ \\
& TC & $78: 129$ & $90: 128$ & 0.577 & 0.488 & $0.860(0.583-1.270)$ \\
& TT & $72: 129$ & $61: 128$ & 0.545 & 0.521 & $1.171(0.770-1.782)$ \\
\hline
\end{tabular}

2 , thereby play important roles in controlling blood pressure [35-38]. The kidney plays a central role in the pathophysiology of EH, and the NCC is physiologically relevant to the development of EH. Based on the previous studies, we inferred a mechanism that the mutations in CUL3 might influence susceptibility to EH. In this study, we analyzed the association of CUL3 rs17479770 and rs3738952 polymorphisms with EH in the Southern Chinese Han population, but several limitations of this study should be mentioned. The main limitation is the relatively small sample size: only 520 participants, including $259 \mathrm{EH}$ patients and 261 normotensive people, were recruited, which is insufficient for an SNP association study of a rarer mutation site. The other limitation is that only two SNPs within the CUL3 gene were analyzed. Additional in-depth studies are needed to confirm the functional importance of CUL3 rs17479770 polymorphism in $\mathrm{EH}$ and to elucidate its precise role in the pathogenesis of $\mathrm{EH}$.

\section{Conclusion}

This study demonstrates that CUL3 rs17479770 is a candidate SNP that could be further examined as a possible protective genetic factor for $\mathrm{EH}$ progression, especially in male population. However, no significant association was detected between CUL3 rs3738952 polymorphism and $\mathrm{EH}$ in the Chinese Han population, and the study of haplotype frequency distributions of CUL3 rs17479770 and rs3738952 in the EH and normotensive groups had no significant association. Our results revealed that the CUL3 rs17479770 TT genotype was associated with protection against $\mathrm{EH}$ in male and all representatives. This study offers a new direction to understand the mechanisms underlying $\mathrm{EH}$ and suggest novel therapeutic targets for the disease treatment. Further population-based genetic studies will be required to confirm our results and consolidate the role of CUL3 on EH in populations living in different environments or regions.

\section{Abbreviations}

$\begin{array}{ll}\text { ANOVA: } & \text { Analysis of variance } \\ \text { BMI: } & \text { Body mass index } \\ \text { BP: } & \text { Blood pressure } \\ \text { BTB: } & \text { Bric-a-brac tramtrack broad complex }\end{array}$

CI: $\quad$ Confidence intervals

CRL: Cullin-RING E3 ubiquitin ligase

CUL3: Cullin-3

CYP: $\quad$ Cytochrome P450

DBP: Diastolic blood pressure

EH: $\quad$ Essential hypertension

GWAS: $\quad$ Genome-wide association studies

HbAlc: Hemoglobin A1c

HNSCC: $\quad$ Head and neck squamous cell carcinoma

HWE: Hardy-Weinberg equilibrium

JNC 7: Seventh report of the Joint National Committee on prevention, election, evaluation, and treatment of high blood pressure

JNC 8: 2014 evidence-based guideline for the management of high blood pressure in adults: report from the panel members appointed to the Eighth Joint National Committee

KLHL3: $\quad$ Kelch-like 3

MALDI-TOF

MS: $\quad$ Matrix-assisted laser desorption/ionization

NCC: $\quad \mathrm{Na}^{+} / \mathrm{Cl}^{-}$cotransporter

NKCC: $\quad \mathrm{Na}^{+} / \mathrm{K}^{+} / 2 \mathrm{Cl}^{-}$cotransporter

OR: Odds ratios

PCR: $\quad$ Polymerase chain reaction

PHAII: $\quad$ Pseudohypoaldosteronism type II

RFLP: Restriction fragment length polymorphism

ROMK: Renal outer medullary potassium channel

SBP: $\quad$ Systolic blood pressure

SNPs: $\quad$ Single-nucleotide polymorphisms

TC: $\quad$ Total cholesterol

TG: $\quad$ Triglyceride

WNK: With-no-lysine kinase.

\section{Additional Points}

Highlights. The CUL3 rs17479770 TT genotype was associated with protection from $\mathrm{EH}$ in male and in the full data set. CUL3 rs17479770 is a possible protective genetic factor for $\mathrm{EH}$ progression.

\section{Conflicts of Interest}

The authors declare that they have no conflicts of interest. 


\section{Authors' Contributions}

Jin $\mathrm{Li}$ and Jing $\mathrm{Hu}$ have contributed equally to this work.

\section{Acknowledgments}

The authors gratefully acknowledge the financial supports by the Science and Technology Program of Guangzhou in China under Grant no. 201509010012.

\section{References}

[1] D. C. Scott, D. Y. Rhee, D. M. Duda et al., "Two distinct types of E3 ligases work in unison to regulate substrate ubiquitylation," Cell, vol. 166, article e24, pp. 1198-1214, 2016.

[2] J. P. Arroyo and G. Gamba, "Advances in WNK signaling of salt and potassium metabolism: clinical implications," American Journal of Nephrology, vol. 35, no. 4, pp. 379-386, 2012.

[3] F. R. Schumacher, F. J. Sorrell, D. R. Alessi, A. N. Bullock, and T. Kurz, "Structural and biochemical characterization of the KLHL3-WNK kinase interaction important in blood pressure regulation," The Biochemical Journal, vol. 460, no. 2, pp. 237-246, 2014.

[4] L. M. Boyden, M. Choi, K. A. Choate et al., "Mutations in kelch-like 3 and cullin 3 cause hypertension and electrolyte abnormalities," Nature, vol. 482, no. 7383, pp. 98-102, 2012.

[5] J. A. McCormick, C. L. Yang, C. Zhang et al., "Hyperkalemic hypertension-associated cullin 3 promotes WNK signaling by degrading KLHL3," The Journal of Clinical Investigation, vol. 124, pp. 4723-4736, 2014.

[6] D. A. Tan, "Changing disease trends in the Asia-Pacific," Climacteric, vol. 14, pp. 529-534, 2011.

[7] C. Weiwei, G. Runlin, L. Lisheng et al., "Cardiovascular disease Chinese report 2015 summary," Chinese Circulation Journal, vol. 31, pp. 617-622, 2015.

[8] C. Fava, M. Ricci, O. Melander, and P. Minuz, "Hypertension, cardiovascular risk and polymorphisms in genes controlling the cytochrome P450 pathway of arachidonic acid: a sexspecific relation," Prostaglandins \& Other Lipid Mediators, vol. 98, no. 3-4, pp. 75-85, 2012.

[9] J. Kunes and J. Zicha, "Developmental windows and environment as important factors in the expression of genetic information: a cardiovascular physiologist's view," Clinical Science (London), vol. 111, no. 5, pp. 295-305, 2006.

[10] Z. Fu, T. Nakayama, N. Sato et al., "Haplotype-based casecontrol study of CYP4A11 gene and myocardial infarction," Hereditas, vol. 149, no. 3, pp. 91-98, 2012.

[11] M. K. Pandey, G. Agarwal, S. M. Kale et al., "Development and evaluation of a high density genotyping 'Axiom_Arachis' array with $58 \mathrm{~K}$ SNPs for accelerating genetics and breeding in groundnut," Scientific Reports, vol. 7, article 40577, 2017.

[12] M. Lu, X. Wang, F. Wang et al., "WNK4 polymorphisms and essential hypertension in the Uyghur population," Clinical and Experimental Hypertension, vol. 31, no. 2, pp. 179-185, 2009.

[13] Y. Cun, J. Li, W. Tang et al., "Association of WNK1 exon 1 polymorphisms with essential hypertension in Hani and Yi minorities of China," Journal of Genetics and Genomics, vol. 38, no. 4, pp. 165-171, 2011.
[14] Z. J. Sun, Y. Li, J. Y. Lu et al., "Association of Ala589Ser polymorphism of WNK4 gene with essential hypertension in a high-risk Chinese population," The Journal of Physiological Sciences, vol. 59, no. 2, pp. 81-86, 2009.

[15] S. Sheth, J. L. Weissfeld, M. Romkes et al., "Germline Variation in NFE2L2/CUL3/KEAP1 and Risk of Head and Neck Squamous Cell Carcinoma (HNSCC)," Journal of Clinical Oncology, vol. 33, Supplement 15, p. 1540, 2015.

[16] S. R. Ibeawuchi, L. N. Agbor, F. W. Quelle, and C. D. Sigmund, "Hypertension-causing mutations in cullin3 protein impair RhoA protein ubiquitination and augment the association with substrate adaptors," The Journal of Biological Chemistry, vol. 290, pp. 19208-19217, 2015.

[17] S. Padmanabhan, O. Melander, T. Johnson et al., "Genomewide association study of blood pressure extremes identifies variant near UMOD associated with hypertension," PLoS Genetics, vol. 6, no. 10, article e1001177, 2010.

[18] B. Mayer, W. Lieb, A. Götz et al., "Association of the T8590C polymorphism of CYP4A11 with hypertension in the MONICA Augsburg echocardiographic substudy," Hypertension, vol. 46, no. 4, pp. 766-771, 2005.

[19] D. Levy, G. B. Ehret, K. Rice et al., "Genome-wide association study of blood pressure and hypertension," Nature Genetics, vol. 41, no. 6, pp. 677-687, 2009.

[20] H. C. Yan, J. H. Liu, J. Li et al., "Association between the CYP4A11 T8590C variant and essential hypertension: new data from Han Chinese and a meta-analysis," PLoS One, vol. 8, no. 11, article e80072, 2013.

[21] B. Xiao, Y. Zhang, W. Niu, P. Gao, and D. Zhu, "Association of ATP1B1 single-nucleotide polymorphisms with blood pressure and hypertension in a Chinese population," Clinica Chimica Acta, vol. 407, no. 1-2, pp. 47-50, 2009.

[22] Y. Wang, X. O. Zhou, Y. Zhang, P. J. Gao, and D. L. Zhu, "Association of the CD36 gene with impaired glucose tolerance, impaired fasting glucose, type- 2 diabetes, and lipid metabolism in essential hypertensive patients," Genetics and Molecular Research, vol. 11, no. 3, pp. 2163-2170, 2012.

[23] Q. Zhu, Z. Y. Fu, and Y. T. Ma, "GW25-e3132 single nucleotide polymorphism of the CYP2J2 gene is associated with essential hypertension in Uygur population in China," Journal of the American College of Cardiology, vol. 4, no. 1, article C9, 2014.

[24] C. L. Laffer, J. V. Gainer, M. R. Waterman et al., "The T8590C polymorphism of CYP4A11 and 20-hydroxyeicosatetraenoic acid in essential hypertension," Hypertension, vol. 51, no. 3, pp. 767-772, 2008.

[25] H. Yang, Z. Fu, Y. Ma et al., "CYP4A11 gene T8590C polymorphism is associated with essential hypertension in the male western Chinese Han population," Clinical and Experimental Hypertension, vol. 36, no. 6, pp. 398403, 2014.

[26] D. E. Stec, R. J. Roman, A. Flasch, and M. J. Rieder, "Functional polymorphism in human CYP4F2 decreases 20-HETE production," Physiological Genomics, vol. 30, no. 1, pp. 74-81, 2007.

[27] A. G. Moraitis, W. E. Rainey, and R. J. Auchus, "Gene mutations that promote adrenal aldosterone production, sodium retention, and hypertension," The Application of Clinical Genetics, vol. 7, pp. 1-13, 2013.

[28] Y. Yu, S. H. Keller, C. V. Remillard et al., "A functional single-nucleotide polymorphism in the TRPC6 gene 
promoter associated with idiopathic pulmonary arterial hypertension," Circulation, vol. 119, no. 17, pp. 23132322, 2009.

[29] A. V. Chobanian, G. L. Bakris, H. R. Black et al., "The seventh report of the Joint National Committee on prevention, detection, evaluation, and treatment of high blood pressure: the JNC 7 report," Jama, vol. 289, no. 19, pp. 2560-2572, 2003.

[30] P. A. James, S. Oparil, B. L. Carter et al., "2014 evidence-based guideline for the management of high blood pressure in adults: report from the panel members appointed to the Eighth Joint National Committee (JNC 8)," Journal of the American Medical Association, vol. 311, no. 5, pp. 507-520, 2014.

[31] Y. Gong, J. Wang, J. Yang, E. Gonzales, R. Perez, and J. Hou, "KLHL3 regulates paracellular chloride transport in the kidney by ubiquitination of claudin-8," Proceedings of the National Academy of Sciences of the United States of America, vol. 112, pp. 4340-4345, 2015.

[32] A. X. Ji and G. G. Privé, "Crystal structure of KLHL3 in complex with cullin3," PLoS One, vol. 8, no. 4, article e60445, 2013.

[33] J. A. McCormick and D. H. Ellison, "The WNKs: atypical protein kinases with pleiotropic actions," Physiological Reviews, vol. 91, no. 1, pp. 177-219, 2011.

[34] K. T. Kahle, A. M. Ring, and R. P. Lifton, "Molecular physiology of the WNK kinases," Annual Review of Physiology, vol. 70, pp. 329-355, 2008.

[35] K. B. Gagnon and E. Delpire, "Molecular physiology of SPAK and OSR1: two Ste20-related protein kinases regulating ion transport," Physiological Reviews, vol. 92, no. 4, pp. 15771617, 2012.

[36] G. Gamba, "The thiazide-sensitive $\mathrm{Na}^{+}-\mathrm{Cl}^{-}$cotransporter: molecular biology, functional properties, and regulation by WNKs," American Journal of Physiology. Renal Physiology, vol. 297, no. 4, pp. F838-F848, 2009.

[37] C. Richardson, K. Sakamoto, P. de los Heros et al., "Regulation of the NKCC2 ion cotransporter by SPAK-OSR1-dependent and -independent pathways," Journal of Cell Science, vol. 124, Part 5, pp. 789-800, 2011.

[38] A. C. Vitari, J. Thastrup, F. H. Rafiqi et al., "Functional interactions of the SPAK/OSR1 kinases with their upstream activator WNK1 and downstream substrate NKCC1," The Biochemical Journal, vol. 397, no. 1, pp. 223-231, 2006. 


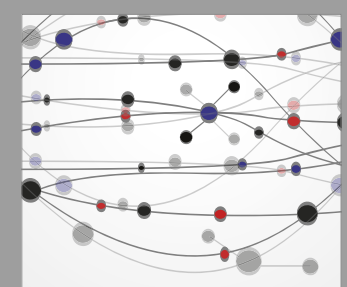

The Scientific World Journal
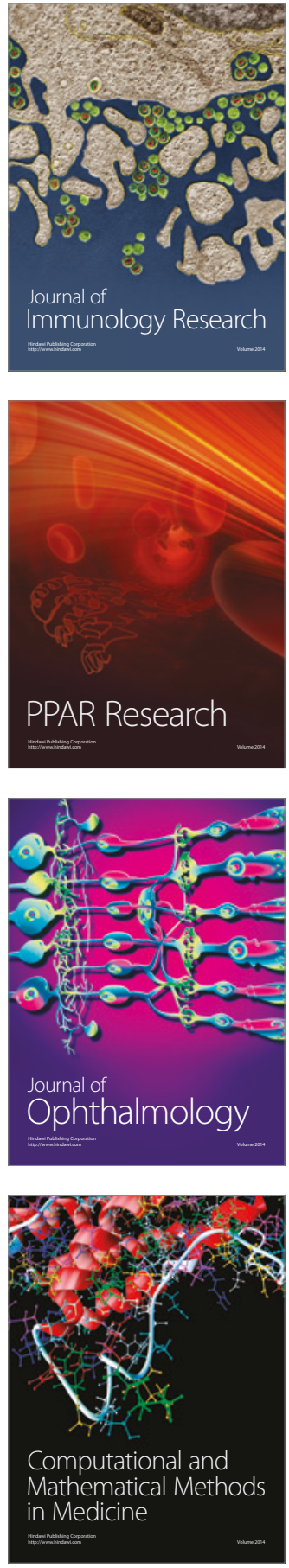

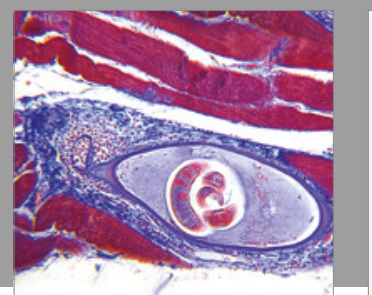

Gastroenterology Research and Practice
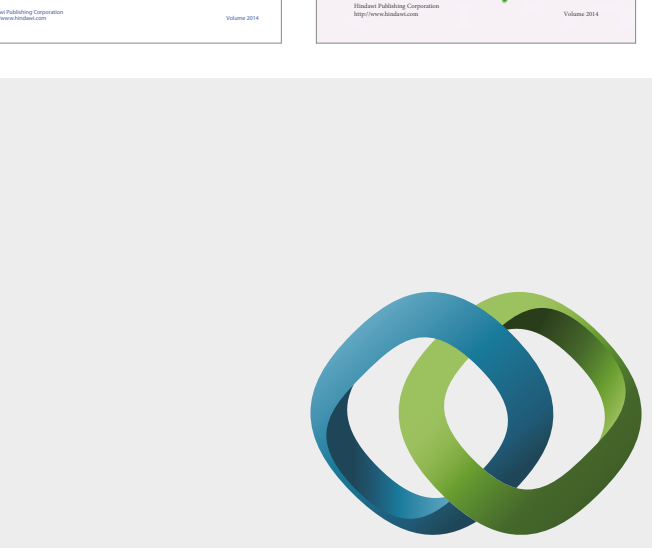

\section{Hindawi}

Submit your manuscripts at

https://www.hindawi.com
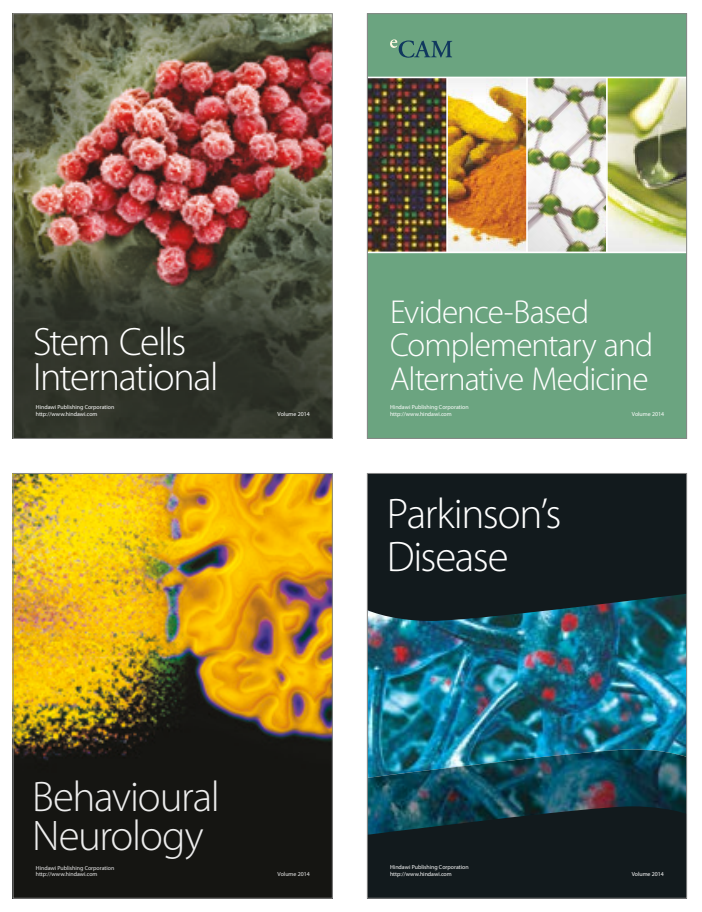


Disease Markers
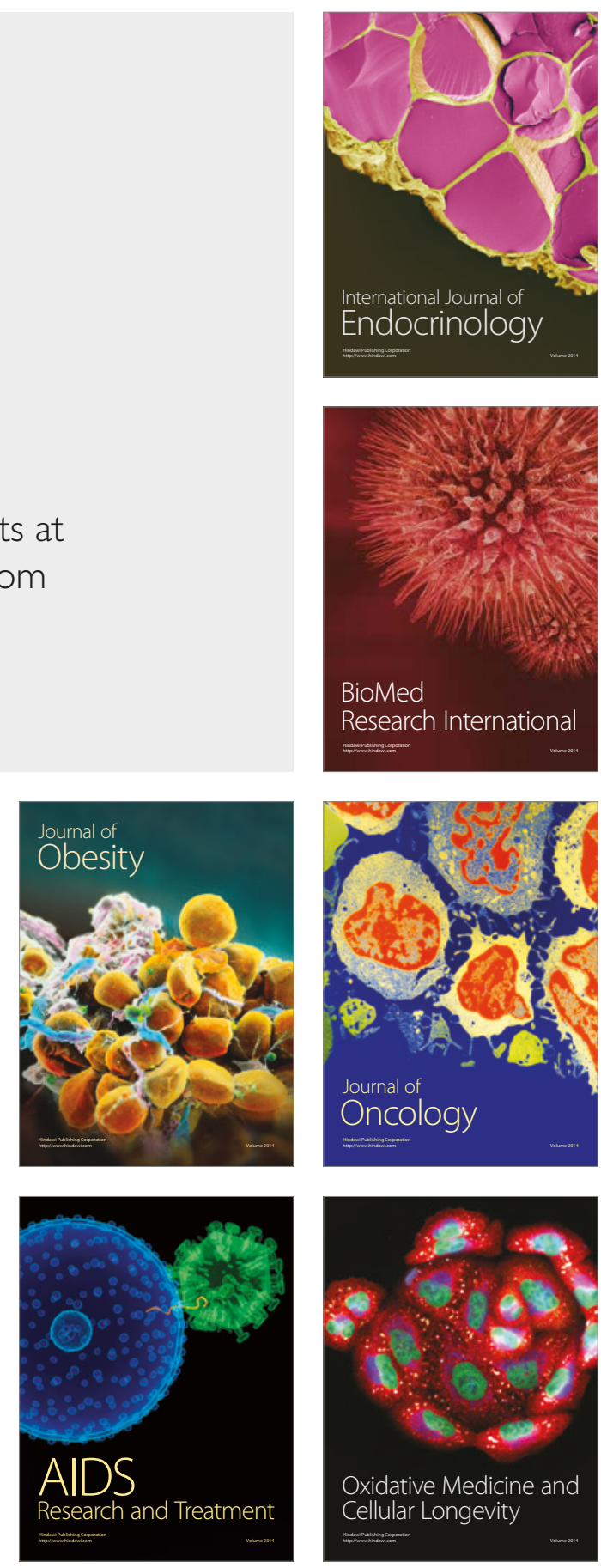